\title{
Strategic Focus and Sustainable Development of Intelligent Management of Large-Scale Events
}

\author{
Yicheng Luo ${ }^{1}$, Jiankang Zhang ${ }^{2 *}$ \\ ${ }^{1,2}$ School of International Economy \& Tourism Management, Zhejiang International Studies University, Hangzhou, \\ Zhejiang 310023, China \\ *Corresponding author. Email: zhangjk@zisu.edu.cn
}

\begin{abstract}
Large-scale event management is the process of integrating and coordinating the people, things, information, funds and other resources invested in large-scale event and transforming them into event products and services. This study combed the large domestic competition intelligence management experience and related theoretical basis, put forward based on the analysis of the whole industry chain big events wisdom management framework, and its where summarized.
\end{abstract}

Keywords: Large-scale event, intelligent management, strategic focus, sustainable development

\section{PREAMBLE}

Traditional event management focuses on the improvement of the efficiency of the event, preferring to the management of people rather than service. However, in fact, due to the imperfect event supervision mechanism, the lack of scientific and reasonable personnel allocation and the lack of management framework, intelligent tools have been added in recent years, but they are only limited to the surface. Sports industry chain of various chain is also a lack of integration between, can't display overall superiority, of leading industry chains did not play a major role, the problems such as chain cannot form organic fusion, lead to the development of sports industry in a quick buck, the blind pursuit of value, does not pay attention to research and development status, such as a dangerous precedent for future market development sports industry [1].Research big events, the innovative construction of intelligent management and sustainable development, is advantageous to the domestic adjustment of the existing management mode, to develop a reasonable and effective event management solution, in improving the efficiency of the events at the same time, increasing the social benefit and economic benefit competition, improving the contestants and the experience of the crowd, so as to achieve win-win effect.

\section{TARGET POSITIONING OF INTELLIGENT MANAGEMENT OF LARGE-SCALE EVENTS}

\subsection{Efficiency}

Large-scale events due to the size and complexity of the content, need to involve a large number of different kinds of external organizations, the interests of different external organizations, different goals and aspirations, easy to conflict or blame, resulting in the event can not be held or delayed, so how to effectively coordinate the tasks between the organizations is a very important topic. Different race processes and work rings are intertwined, only to balance the work of various departments, efficient allocation of tasks, so that all departments and personnel have sincere cooperation, focusing on efficiency, in order to achieve high-quality tasks. Whether it is efficient plays a decisive role in the success of sports events.

\subsection{Socialization}

As a social organization with humanistic nature, the basic attributes of sports events should also follow the fundamental value principle of "people-oriented" in sports [2]. In the process of event management, we should not only pay attention to environmental protection and resource conservation, but also pay attention to humanistic care. The Olympic health organization announced in the "Olympic sports in the 
21st century agenda" Olympic action plan for sustainable development, including how to change human consumption habits, hygiene and health, sports equipment facilities, management and utilization of water resources, waste and air pollution, ecological and environmental quality and global biodiversity protection and a series of content. This is not only a practical guide for the Olympics, but also provides advice and methods for future sporting events [3].

\subsection{Whole industrial chain}

Sports management system for all-round optimization of the industrial chain, its biggest advantage is to continuously optimize the management of the core business layer and business process, so as to greatly reduce the cost of international management and management of Chinese sports enterprises and organizations, enhance the comprehensive competitiveness of the international market. In recent decades, the content of competitions has not only been limited to competitions, but also a series of activities before and after competitions, such as the performance industry derived from competitions, the IP industry of competition image, and the use of venues after competitions.

\section{CONSTRUCTION OF THE FRAMEWORK OF INTELLIGENT MANAGEMENT OF LARGE-SCALE EVENTS}

\subsection{Improve the Management Environment of Event Operation}

The operation environment is the basis of event management and the basis of event management. However, there is a lack of legislation on sports events in China, and there are even fewer laws on the management of sports events. There are only a small number of policies and regulations as a reference for problems in the management of sports events, and the sports law has not been revised according to the actual situation of sports development since it was revised in 2009, which makes the whole sports field lack strong protection. Without the support of complete relevant laws and regulations, the competition market cannot be fully developed, and the market competition is prone to unfairness and justice, which is very unfavourable to the management of sports events and the development of the entire sports industry. Chinese people 's cognition of sports events is also insufficient, which hinders the development of the sports industry. Therefore, first of all, government departments should pay attention to and fully understand the problems existing in the development of the current sports industry, formulate relevant policies, and modify the sports law in combination with facts, so as to provide a good environment for the development of the sports industry. Secondly, to further promote the comprehensive improvement of competition market rules, promote reform, strengthen the government and market cooperation. Third, further carry out relevant popular science for citizens to improve their sports and cultural literacy.

\subsection{Build the Whole Industry Chain of Event Management}

If a perfect operation environment is the basis of intelligent management of sports events, then a complete industry chain of event management can promote the sustainable development of the sports industry and make full use of resources. Has yet to have industry chain for sports management, and it is the needs of the sports industry, China's comprehensive national strength increasing, our country society constantly improve the level of sports industry in our country for a larger market, social competition environment change more pressure for the development of sports industry in China, in the face of foreign complete event management market and good sports development environment, a suitable for our country the improvement of the social characteristics of event management industry chain is needed in our country. Therefore, the competition management department should further scientific analysis of China's social and market needs; Improve the core ability of sports enterprises, improve the management level and competitiveness; Improve the information system related to the event; Based on the Internet platform, a complete industry chain of event management from tournament preparation to post-match feedback has been formed. Build a database to gather information from all sides and provide a scientific basis for decision making.

\subsection{Strengthen the Supervision Mechanism of Multiple Participation}

After the formation of the event management industry chain, it is also required to strengthen the scientific construction and effective operation of government and market supervision system is the core guarantee of event management. It is also necessary for the active participation of non-government commercial organizations in order to deal with the problems that may arise in the course of the operation and management of sports events in a timely and effective manner, combine the intelligent information technology means and platforms of sports, do a good job in the quality assurance and management coordination of the quality of event services, as well as the supervision on and offline. China's existing supervision system has the form, lack of feedback and other issues. In the event, management supervision should adopt a dynamic management approach, increase the intensity of 
supervision, so that the whole industry chain supervision, to provide accurate and timely information and services for management. The establishment of intelligent diagnosis and automatic adjustment system, through a variety of data, mining and analysis, to assist managers to effectively find problems to solve problems, improve the reliability, effectiveness and intelligence of the supervision system [4].

\subsection{Establish a Networked Feedback System after Competition}

One of the ultimate goals of event management is also to better serve people, build a public online participation network platform to achieve effective and timely feedback after the game, unlike the previous unilateral output, the construction of post-match feedback system can achieve the exchange between managers and participants, open and fair feedback platform is conducive to participants to exercise their own civil rights and interests, is conducive to the next improvement of managers, and constantly improve the management model, better serve the participants. Every feedback and comment, as well as responses, is recorded on a big data platform and can be viewed by the relevant oversight department or the public through online inquiries. Traditional event management systems lack feedback, and traditional managers tend to manage events based on their own experience, and such decisions often lack science and progress. The intelligent event management and feedback system will be combined, the system collects all kinds of relevant data and information, through big data and other related technologies to the event management process collected information processing, mining and analysis, and then through intelligent diagnosis and analysis results, the transmission of effective information to managers, not only to make full use of information, but also reduce the loss of manpower, can promote the entire management system sustainable, healthy, forward and perfect.

\section{SUSTAINABLE DEVELOPMENTOF INTELLIGENT MANAGEMENT OF LARGE-SCALE EVENTS}

\subsection{Change of Management Thinking: Build People-oriented Management}

One of the biggest differences between modern event management and traditional event management is the change of management thought of humanism. The position of people in sports event management has evolved from being managed at the beginning to being served, and the means and methods of sports event management have become more and more humanized. Hong Kong Marathon [4] shows the full humanistic thought, which mainly includes four aspects: changing the concept, making full use of the network, detailed management and strengthening cooperation and cooperation. The starting point of the Hong Kong Marathon is from managing the athletes to serving the athletes, from finishing the race on schedule to making the runners perform and leave a good impression on the city. Communicate with the public through the Internet, timely listen to suggestions for the improvement of event management, not only before the race, but also pay attention to the relevant evaluation after the race, lay a good foundation for the next race, strive for excellence; The training of volunteers has also been strengthened, and a scientific volunteer training system has been established to give participants a better experience. Finally, fully mobilize all departments to realize the overall coordinated operation of the event and improve the management efficiency of the event. It also established the evaluation and feedback mechanism of the competitors to the event, so as to achieve the balance of social benefits and economic benefits, improve the service level of the next competition, and establish a better brand image. The 2018 PyeongChang Winter Olympics in South Korea has fully integrated 5G technology on the basis of traditional event coverage, providing mobile users with an immersive experience service to enhance users' sense of presence and interaction at the event. It is not only the technological level of innovation, but also the thinking level of progress. Humanistic management can not only improve efficiency, but also help to build a harmonious, coordinated and sustainable environment for sports events.

\subsection{Innovation of Management Carrier: Combined with Network Management}

As a sporting event, it must rely on realistic venues and facilities. The management of objects in sports events is mainly the management of equipment and the management of venues. The intelligent management of equipment to the domestic equestrian competition, for example, the scale of equestrian competition, the corresponding race equipment individual volume is also larger, and a larger number of such equipment manual treatment is time-saving and inefficient, after the continuous development of the times, China's production supporting technology and related hardware facilities gradually improved, RFID this technology can be widely used in the production and management of such equipment, RFID (radio frequency identification) is Radio Frequency The abbreviation for The Name. Based on the principle of non-contact data communication between e-reader and electronic label, it can finally achieve the basic purpose of accurately identifying the target. Specific technical treatment methods are to put corresponding electronic labels on the required equipment, to help event managers to achieve the continuous management of the game equipment, control the access to the equipment library 
process, to achieve the sharing of equipment use records. The intelligent management of the venue is currently mainly during and after the competition. The intelligent management of the venue of equestrian events relies on the Internet and related information sensing equipment, through networking with the information calculation center, to track the status of athletes and the use of the venue, timely update the information of the venue, facilitate the timely use of athletes and reasonable arrangement of practice time. Unlike traditional event management, stadiums and facilities are now more than just a venue and tool for competitions, improving the efficiency of match management and improving the quality of service is only the most basic foothold of the venues, and sustainable post-match management will be an important topic in the future sports industry chain [5].

\subsection{The Breakthrough of Management Mode: Reconstructing Information Management}

The collection and processing of information analysis is the core of the wisdom of the event. With the development of the times and technological innovation, information management gradually from data management to intelligent management changes. Intelligent management of information can greatly improve the processing speed of information, facilitate the sharing and use of information, thereby improving the efficiency of the event. The 2014 World Cup in Brazil [ 6 ] was more intelligent in the use and analysis of match information: it also used a system called Goal Control's M2M doorline technology system, using 14 high-speed cameras to transmit photos to a data spacer at the top of the stadium, after a comprehensive analysis of the data, and then transmitted the results of the analysis to a special watch worn by the referee in advance. If the machine detects that the ball has passed the white line, the goal will be displayed on the watch, which is less than 1 second of the calculation process, can effectively prevent the referee's personal factors caused by the misjudgment, thus ensuring the fairness and fairness of each game. M2M technology can be used in extreme conditions such as high temperature and high pressure, can also monitor the temperature of objects, for the monitoring of the body temperature of athletes, in the event of abnormal body temperature of athletes, timely warning to coaches. Combining information management in event management can fully integrate human sensibility and machine rationality, improve the efficiency of event management, and at the same time, can give effective conclusions more fairly and impartially, detect anomalies in a timely manner and make reasonable responses.

\section{CONCLUSION}

With the vigorous development of sports events at home and abroad, the management of sports events is becoming more and more important. The intelligent management of large-scale events utilizes modern scientific and technological means, relies on the core idea of the whole industry chain, and has a great space for development. With the background of the digital age, relying on other scientific thought theories such as the whole industry chain, the degree of intelligent management of large-scale events in China will be rapidly improved, and the management efficiency will become effective and efficient. At the same time, we should also pay attention to big data and networks as a means of intelligent management. There is a certain risk, in the convenience of management of the event, but also increased public privacy exposure, the possibility of personal information leakage, so we cannot rely entirely on smart technology. How to increase the intelligent management of large-scale events under the condition of ensuring the security of information is a problem that needs to be further studied in the future.

\section{ACKNOWLEDGMENTS}

This work was supported by the Zhejiang Provincial Social Science Planning Project "Communication Technology Deconstruction and Practice Orientation of the Intelligent Asian Games" (20NDJC159YB).

\section{REFERENCES}

[1] Huo Jun. Research on Optimization and Development Strategy of Sports Industry Chain [J]. Sports Science Research,2011,15(05):11-14.

[2] Xing Zunming. Theoretical and Empirical Research on Optimal Management of Large Sports Events in China [D]. Fujian Normal University, 2008.

[3] Li Shanshan, Li Qiang. Research on Sports Event Operation and Risk Management [J]. Computer Products and Circuits,2020(07):286-287.

[4] Yu Lixian. Research on Equestrian Event Management under the Environment of Internet of Things [J]. Asia Pacific Education,2016(32):12-13.

[5] Lin Yao.M2M Injects Intelligent Energy into Sports Events [J]. Software and Information Service,2014(10):12. 